\title{
Design and Implementation of Stator Resistance Identifier Based on Fuzzy Control
}

\author{
Lianfei Wang \\ Jinan Engineering Vocational Technical College, Jinan 250200, China \\ 376242301@qq.com
}

\section{Keywords: Stator resistance; Fuzzy control; Robustness}

\begin{abstract}
The change of stator resistance has an important influence on the performance of asynchronous motor direct torque control system. Accurate acquisition of stator resistance is very important in high-performance motor control system. According to fuzzy control theory, we devise a stator resistance identifier. On this basis, the direct torque control system of asynchronous motor is designed by using MATLAB software. At the same time, through this simulation, we find the error of identified stator resistance is small, the system respond is quick, and the robustness is good.
\end{abstract}

\section{Introduction}

Asynchronous motor direct torque control is a high-Performance AC speed regulation technology [1]. The basic idea is to choose the suitable stator voltage space vector to realize the rapid response of the magnetic torque of the AC motor, according to the need of the AC motor's torque.

The direct torque control is on account of the stator coordinate system to study this mathematical model of AC motor and control the torque and flux linkage of motor.

The direct torque control is on account of the stator coordinate system to study the mathematical model of AC motor, regulate motor torque and magnetic chain. This signal processing is simple, and the control signal used for observers is able to make a direct and clear judgement of the physical process of AC motor[2].

Direct torque control is based on stator flux linkage, so we can observe stator flux linkage only by explicit stator resistance[3].

The relationship between stator resistance and stator current is nonlinear, so they can not be expressed by accurate mathematical models. If we use the traditional mathematical model, it is difficult to get the stator resistance value accurately. The fuzzy control is not dependent on the precise mathematical model of the controlled object. It only needs to use the practical experience accumulated by the professional personnel to model the control rules, and then use the reasoning to achieve the optimal control of the control quantity. Most of the former stator resistance identifiers are based on the temperature and variation. Its disadvantage is that the thermistor should be installed in the stator, which can reduce the mechanical characteristics of the motor, and it is difficult to erect. A stator resistance estimator is designed in this paper[4], with the change of stator current error $\mathrm{E}$ and error of the quantity of $\mathrm{E}$ as input variables. The variation of the stator resistance Delta Rs is the output variable. In the low speed running state, the speed of the response is improved, the torque ripple is smaller, and the influence of the nonlinear factors can be overcome, and the parameters of the adjusted object are robust.

\section{Design of Stator Resistance Iidentifier}

The Basic Idea of Fuzzy Control. Fuzzy control belongs to the category of intelligent control, and it is a form of human intelligence. The successful application of fuzzy control in industry, home appliances and high technology area fully shows that fuzzy control has great potential for development and application. Because of its easy to use, simple, good effect and so on.

It is mainly applied in all kinds of control systems, especially in the case of model uncertain, nonlinear, large time delay systems. The schematic diagram of the fuzzy controller is given in Fig. 1. 


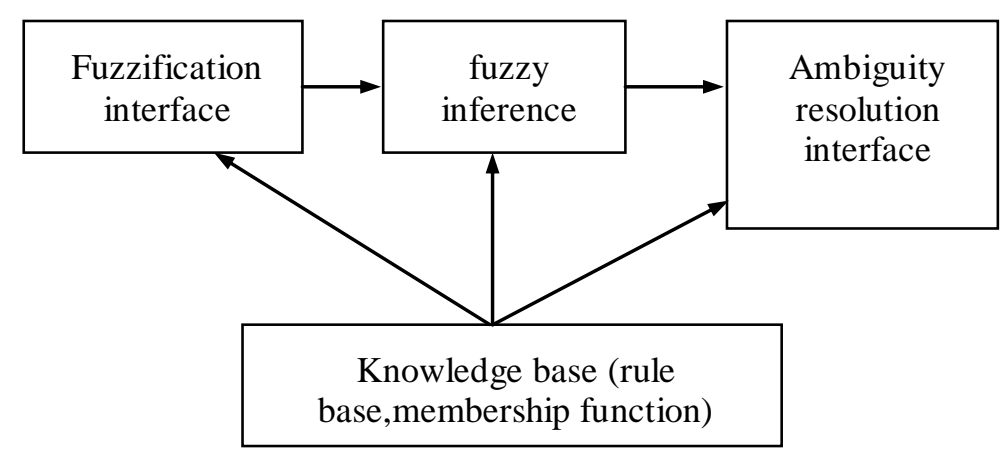

Fig 1 The schematic diagram of the fuzzy controller

Design of Stator Resistance Iidentifier. According to the theory of motor, in the static coordinate system of alpha and beta, the mathematical model of asynchronous motor is described as follows:

Voltage equation:

$$
\begin{aligned}
& \mathrm{u}_{\alpha 1}=\mathrm{R}_{1} \mathrm{i}_{\alpha 1}+\mathrm{p} \psi_{\alpha 1} \\
& u_{\beta 1}=R_{1} i_{\beta 1}+p \psi_{\beta 1} \\
& u_{\alpha 2}=R_{2} i_{\alpha 2}+p \psi_{\alpha 2}+\omega \psi_{\beta 2} \\
& u_{\beta 2}=R_{2} i_{\beta 2}+p \psi_{\beta 2}+\omega \psi_{\alpha 2}
\end{aligned}
$$

Magnetic chain equation:

$$
\begin{aligned}
& \psi_{\alpha 1}=L_{s} i_{\alpha 1}+L_{m} i_{\alpha 2} \\
& \psi_{\beta 1}=L_{s} i_{\beta 1}+L_{m} i_{\beta 2} \\
& \psi_{\alpha 2}=L_{m} i_{\alpha 1}+L_{r} i_{\alpha 2} \\
& \psi_{\beta 2}=L_{m} i_{\beta 1}+L_{r} i_{\beta 2}
\end{aligned}
$$

The Eq. 2 is substituted for Eq. 1 and we use matrix representation. The voltage of the model of this asynchronous motor expressed by matrix equation can be obtained by using the matrix equation.

The voltage of the mathematical model of the asynchronous motor expressed by matrix equation is:

$$
\left[\begin{array}{l}
u_{\alpha 1} \\
u_{\beta 1} \\
u_{\alpha 2} \\
u_{\beta 2}
\end{array}\right]=\left[\begin{array}{cccc}
R_{1}+L_{s} p & 0 & L_{m} p & 0 \\
0 & R_{1}+L_{s} p & 0 & L_{m} p \\
L_{m} p & \omega L_{m} & R_{2}+L_{r} p & \omega L_{r} \\
-\omega L_{m} & L_{m} p & -\omega L_{r} & R_{2}+L_{r} p
\end{array}\right]\left[\begin{array}{c}
i_{\alpha 1} \\
i_{\beta 1} \\
i_{\alpha 2} \\
i_{\beta 2}
\end{array}\right]
$$

Under the alpha beta system, the motor's electromagnetic torque[5]can be expressed as:

$$
T_{e}=n_{p} L_{m}\left(i_{\beta 1} i_{\alpha 2}-i_{\alpha 1} i_{\beta 2}\right)
$$

The stator resistance identifier[6] designed in this paper uses the stator current deviation E and the variation quantity of this deviation delta e as the input variable, and the output variable is the variation amount of the stator resistance Delta Rs.

The output variable is the stator resistance change quantity Rs. 
Is (k) is the actual value of stator current[7].

$$
i_{s}(k)=\sqrt{i_{\alpha s}^{2}+i_{\beta s}^{2}}
$$

i $\alpha$ s and i s represent the weight of the stator current in the static coordinate system of the alpha and beta axis, respectively.

The output is the change value of the stator resistance of delta Rs. The input selection e (k), delta e (k) and the output selection of delta Rs are defined respectively 5 fuzzy subsets \{NL, NS, ZE, PS, PL\}. The change value Delta Rs of the stator resistance can be obtained by fuzzy decision. The initial value Rs0 and the output value Delta Rs of the controller are added, and the stator resistance value can be obtained, that is to say, Rs=Rs0+ Delta Rs.

The control range of the error e of the stator current vector is $-1.2 \mathrm{~A}$ to $+1.2 \mathrm{~A}$, and this control range of the current error change quantity delta e is $-0.5 \mathrm{~A}$ to $+0.5 \mathrm{~A}$. The control range of delta $\mathrm{Rs}$ is from -0.006 to $+0.012 \Omega$, and their membership function curves are selected as the trigonometric shape with good linearity. Fig. 2 is the distribution curve of the membership function of the current error e.

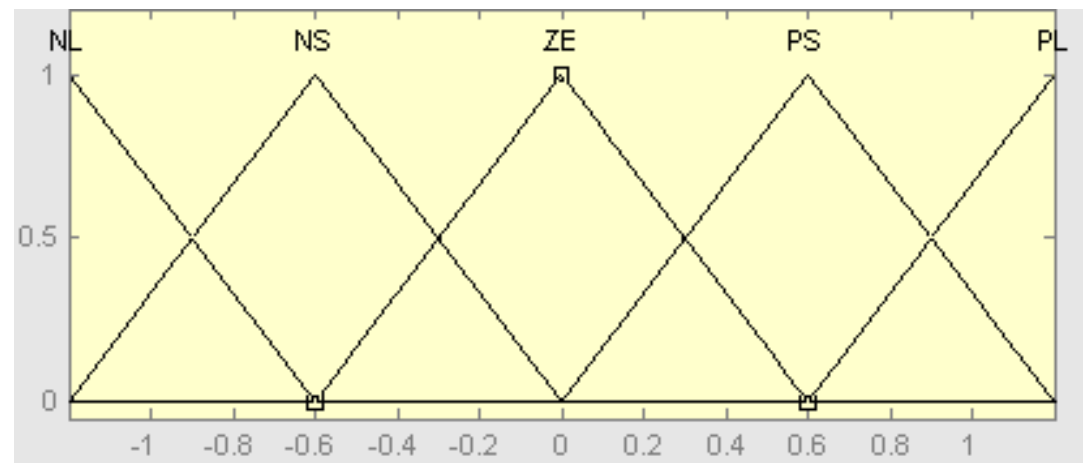

Fig 2 the distribution curve of the membership function of the current error e

Taking Fig. 2 as an example, the membership functions of each fuzzy set of current error E are:

$$
\begin{aligned}
& u_{N L}(e)=\left\{\begin{array}{cc}
0 & e>-0.6 \\
1 & e \leq-1.2 \\
-\frac{5}{3}(e+0.6) & -1.2<e \leq-0.6
\end{array}\right. \\
& u_{N S}(e)=\left\{\begin{array}{cc}
0 & e \leq-1.2 \text { or } \geq 0 \\
\frac{5}{3}(e+1.2) & -1.2<e \leq-0.6 \\
-\frac{5}{3} e & -0.6<e<0
\end{array}\right. \\
& u_{Z E}(e)=\left\{\begin{array}{cc}
0 & e \leq-0.6 \text { or } \geq 0.6 \\
\frac{5}{3}(e+0.6) & -0.6<e \leq 0 \\
-\frac{5}{3}(e-0.6) & 0<e<0.6
\end{array}\right.
\end{aligned}
$$




$$
\begin{aligned}
& u_{P S}(e)=\left\{\begin{array}{cc}
0 & e \leq 0 \text { or } \geq+1.2 \\
\frac{5}{3} e & 0<e \leq 0.6 \\
-\frac{5}{3}(e-1.2) & 0.6<e<1.2
\end{array}\right. \\
& u_{P L}(e)=\left\{\begin{array}{cc}
0 & e \leq 0.6 \\
\frac{5}{3}(e-0.6) & 0.6<e<1.2 \\
1 & e \geq+1.2
\end{array}\right.
\end{aligned}
$$

The selection of these values is based on the parameters and performances of asynchronous motors[8]. The scheme is not unique, and it needs to be optimized in actual operation.

Then, we set up the domain, quantized e into 7 levels of $\{-1.2,-0.8,-0.4,0,0.4,0.8,1.2\}$, and respectively expressed as $\{(1),(2),(3),(4),(5),(6),(7)\}$, that is, the fuzzy variables are partitioned. and the following tables can be obtained by the membership function curve.

Table 1 assignment table of fuzzy variable e

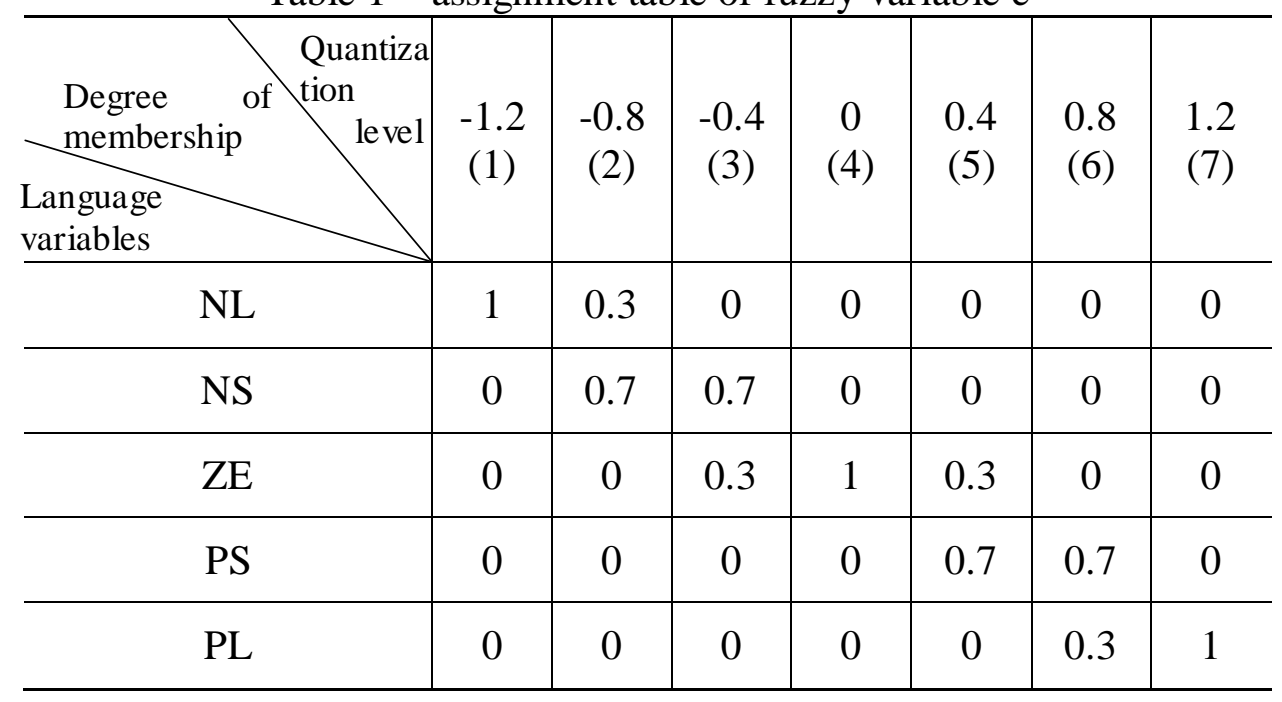

Similarly, the delta e, delta Rs quantization into 7 grades, can be obtained:

Table 2 assignment table of fuzzy variable $\Delta \mathrm{e}$

\begin{tabular}{c|c|c|c|c|c|c|c}
\hline $\begin{array}{c}\text { Degree of } \\
\text { membership } \\
\begin{array}{l}\text { Language } \\
\text { variables }\end{array}\end{array}$ & $\begin{array}{c}\text { Quantiza } \\
\text { tion } \\
\text { NL }\end{array}$ & $\begin{array}{c}-0.4 \\
(2)\end{array}$ & $\begin{array}{c}-0.1 \\
(3)\end{array}$ & $\begin{array}{c}0 \\
(4)\end{array}$ & $\begin{array}{c}0.1 \\
(5)\end{array}$ & $\begin{array}{c}0.4 \\
(6)\end{array}$ & $\begin{array}{c}0.5 \\
(7)\end{array}$ \\
\hline $\mathrm{NS}$ & 0 & 0.5 & 0.3 & 0 & 0 & 0 & 0 \\
\hline $\mathrm{ZE}$ & 0 & 0 & 0.7 & 1 & 0.7 & 0 & 0 \\
\hline $\mathrm{PS}$ & 0 & 0 & 0 & 0 & 0.3 & 0.5 & 0 \\
\hline $\mathrm{PL}$ & 0 & 0 & 0 & 0 & 0 & 0.5 & 1 \\
\hline
\end{tabular}


Table 3 assignment table of fuzzy variable $\Delta$ Rs

\begin{tabular}{c|c|c|c|c|c|c|c}
\hline $\begin{array}{l}\text { Degree of tion } \\
\text { membership } \\
\begin{array}{l}\text { Language } \\
\text { variables }\end{array}\end{array}$ & $\begin{array}{c}-0.00 \\
6 \\
(1)\end{array}$ & $\begin{array}{c}-0.00 \\
4 \\
(2)\end{array}$ & $\begin{array}{c}-0.0012 \\
(3)\end{array}$ & $\begin{array}{c}0 \\
(4)\end{array}$ & $\begin{array}{c}0.002 \\
(5)\end{array}$ & $\begin{array}{c}0.006 \\
(6)\end{array}$ & $\begin{array}{c}0.012 \\
(7)\end{array}$ \\
\hline $\mathrm{NL}$ & 1 & 0.3 & 0 & 0 & 0 & 0 & 0 \\
\hline $\mathrm{NS}$ & 0 & 0.7 & 0.4 & 0 & 0 & 0 & 0 \\
\hline $\mathrm{ZE}$ & 0 & 0 & 0.6 & 1 & 0.6 & 0 & 0 \\
\hline $\mathrm{PS}$ & 0 & 0 & 0 & 0 & 0.4 & 0.9 & 0 \\
\hline $\mathrm{PL}$ & 0 & 0 & 0 & 0 & 0 & 0.1 & 1 \\
\hline
\end{tabular}

According to the input variables of e and delta e,output variables of delta Rs, fuzzy control rate is Established.Each of the control rules is described by $\mathrm{e}(\mathrm{k})$, delta $\mathrm{e}(\mathrm{k})$ and delta $\mathrm{R}(\mathrm{s})$. The fuzzy inference rules of resistance deviation delta $\mathrm{R}(\mathrm{s})$ from current deviation $\mathrm{e}(\mathrm{k})$ and current deviation rate delta $\mathrm{e}(\mathrm{k})$ are as follows:

If $\mathrm{e}(\mathrm{k})$ is defined as $\mathrm{A}$ and $\Delta \mathrm{e}(\mathrm{k})$ is defined as $\mathrm{B}$ then $\Delta \mathrm{R}(\mathrm{s})$ is $\mathrm{C}$

In the formula, $\mathrm{A}, \mathrm{B}$ and $\mathrm{C}$ belong to their fuzzy subset respectively.

By max min inference,we can get the fuzzy control table delta Rs. There are 25 Rules of fuzzy rule.

Table 4 Fuzzy control table of stator resistance identification

\begin{tabular}{c|c|c|c|c|c}
\hline $\mathrm{e}$ & $\mathrm{PL}$ & $\mathrm{PS}$ & $\mathrm{ZE}$ & $\mathrm{NS}$ & $\mathrm{NL}$ \\
\hline $\mathrm{PL}$ & $\mathrm{PL}$ & $\mathrm{PL}$ & $\mathrm{PL}$ & $\mathrm{PS}$ & $\mathrm{ZE}$ \\
\hline $\mathrm{PS}$ & $\mathrm{PL}$ & $\mathrm{PL}$ & $\mathrm{PS}$ & $\mathrm{ZE}$ & $\mathrm{NS}$ \\
\hline $\mathrm{ZE}$ & $\mathrm{PL}$ & $\mathrm{PS}$ & $\mathrm{ZE}$ & $\mathrm{NS}$ & $\mathrm{NL}$ \\
\hline $\mathrm{NS}$ & $\mathrm{PS}$ & $\mathrm{ZE}$ & $\mathrm{NS}$ & $\mathrm{NL}$ & $\mathrm{NL}$ \\
\hline $\mathrm{NL}$ & $\mathrm{ZE}$ & $\mathrm{NS}$ & $\mathrm{NL}$ & $\mathrm{NL}$ & $\mathrm{NL}$ \\
\hline
\end{tabular}

The most commonly used methods of defuzzification include the maximum membership method, the area barycenter method, the coefficient weighted average method, the maximum average method and so on[9]. In this system, the fuzzy relation is processed by the maximum membership method, and the required fuzzy control query table of delta Rs is obtained, which is stored in the computer. In real-time control, according to the input variables of the region, we can get the desired value of delta Rs directly through the query. 
Table 5 Query table of $\Delta$ Rs

\begin{tabular}{c|c|c|c|c|c|c|c}
\hline & 1 & 2 & 3 & 4 & 5 & 6 & 7 \\
\hline 1 & -0.006 & -0.006 & -0.006 & -0.006 & -0.004 & -0.0012 & 0 \\
\hline 2 & -0.006 & -0.006 & -0.006 & -0.004 & -0.0012 & 0 & 0.002 \\
\hline 3 & -0.006 & -0.006 & -0.004 & -0.0012 & 0 & 0.002 & 0.006 \\
\hline 4 & -0.006 & -0.004 & -0.0012 & 0 & 0.002 & 0.006 & 0.012 \\
\hline 5 & -0.004 & -0.0012 & 0 & 0.002 & 0.006 & 0.012 & 0.012 \\
\hline 7 & -0.0012 & 0 & 0.002 & 0.006 & 0.012 & 0.012 & 0.012 \\
\hline & 0 & 0.002 & 0.006 & 0.012 & 0.012 & 0.012 & 0.012 \\
\hline
\end{tabular}

The value of a new delta Rs is obtained from the query table, which is added to the value of the Rs in the data memory, that is Rs (k-1), and as the new Rs value, that is Rs (k), takes part in the calculation of the direct torque control, and the corrected Rs value is used as the initial value added to the delta Rs after the next fuzzy estimation[10].

$$
R_{s}(k)=\Delta R_{s}+R_{s}(k-1)
$$

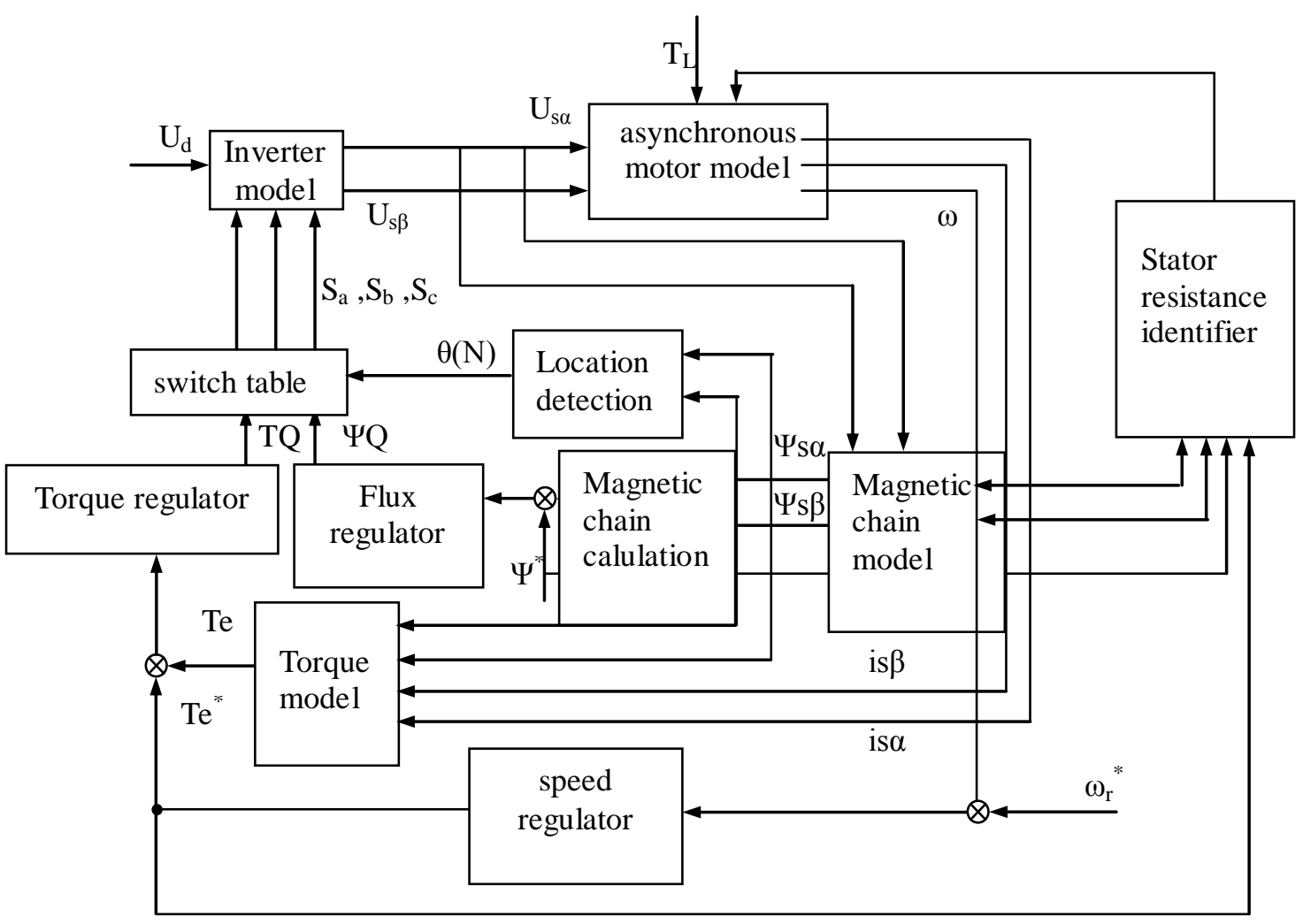

Fig 3 system simulation model with stator resistance identification 


\section{System Simulation and Results}

In this paper, a model of an asynchronous motor direct torque control system is established in the MATLAB simulation environment[11].

The characteristics of the stator resistance identifier are explained, and the system simulation is carried out[12].Figure 3 is the simulation model of this system and the results of simulation are shown in Fig. 4. The main data of theasynchronous motor are as follows: $\mathrm{PN}=2.2 \mathrm{~kW}, \mathrm{f}=50 \mathrm{~Hz}$, $\mathrm{Vn}=380 \mathrm{~V}, \mathrm{In}=3.5 \mathrm{~A}, \mathrm{Rs}=6.518 \Omega, \mathrm{Rr}=5.937 \Omega, \mathrm{L} \delta=0.031 \mathrm{H}, \mathrm{Lm}=0.615 \mathrm{H}, \mathrm{J}=1.151 \mathrm{~kg} . \mathrm{m} 2, \mathrm{p}=2$, $\mathrm{Te}=8 \mathrm{~N} \cdot \mathrm{m}^{2}$ 。

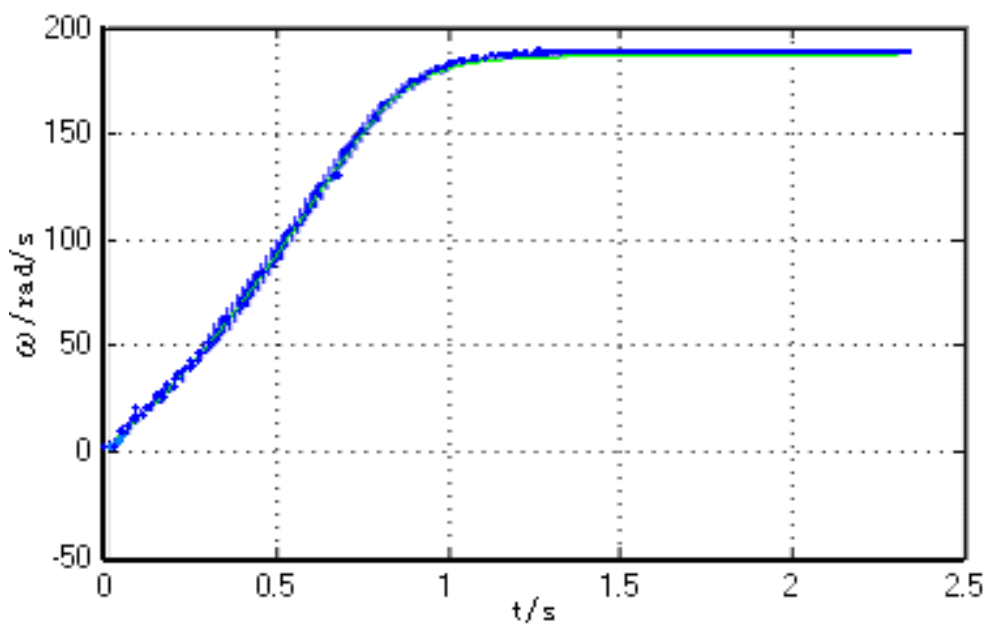

Fig 4(a) speed response curve

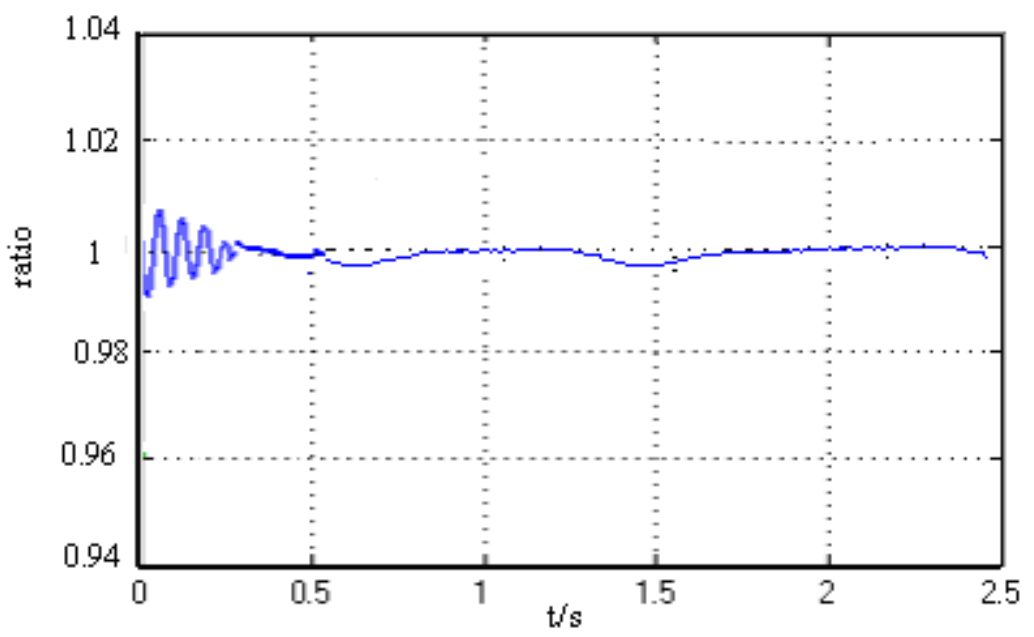

Fig 4(b) stator resistance estimation

\section{Concluding Remarks}

In this paper, a stator resistance identifier is designed based on fuzzy control theory . The simulation results indicate that the identification resistance is very close to the actual resistance. The direct torque control system with the identifier has good dynamic and static characteristics, and the speed response is fast and the fluctuation is small.This shows the correctness and feasibility of the theory. 


\section{References}

[1] Y.W Hu,L.Zhong etc, Direct Torque Control of an Induction Motor Using fuzzy logic,IEEE, 1997,767-772.

[2] Toshihiko Noguchi, Masaki Yamamoto and Isao Takahashi, Enlarging Switching Frequency in Direct Torque-Controlled Inverter by Means of Dithering, IEEE TRANSACTIONS, Ind. Applications ,1999,35(6):1358 1365.

[3] Muhammed Fazlur Rahman, Md Enamul Haque and Tang Lix-in. Problems associated with the Direct Torque Control of an Interior Permanent-magnet Synchronous Motor Drive and their Remedies [J].IEEE Trans. on Industrion Electronics, 2004,51 (4): 799-809.

[4] S M ir,M E lbuluk and D Zinger. PI and fuzzy estimators for tuning the stator resistance in direct torque control of induction machines[J]. IEEE Transactions on Power Electronics, 1998,13(2):279 -287.

[5] Muhammed Fazlur Rahman,Md. Enamul Haque and Tang Lixin. Problems associated with the direct torque control of an interior permanent-magnet synchronous motor drive and their remedies[ J]. IEEE Transactions on Industrial Electronics,2004,51(4):799 -809.

[6] SMir,M Elbuluk and D Zinger. PI and fuzzy estimators for tuning the stator resistance in direct torque control of induction machines[J]. IEEE Transactions on Power Electronics, 1998,13(2):279 -287.

[7] Deng J L. Improvement of direct torque control low speed performance by using fuzzy logic technique[J]. Proceedings of the 2006 IEEE International Conference on Mechatronics and Automation, 2006.

[8] HUNG-CHING LU and CHENG-HUNG TSAI.Grey-fuzzy implementation of Direct Torque Control of induction machines.Electric Machine and Power System,28:1127-1139,2000.

[9] Romeral L., Arias A. and Aldabas E. Novel Direct Torque Control Scheme With Fuzzy Adaptive Torque-Ripple Reduction[J]. IEEE Transaction on Power Electronics, 2003, 50(3): 487-493.

[10] S.M.Elbuluk. "PI and Fuzzy Estimators for Turning the Stator Resistance in Direct Torque Control of Induction Machine",IEEE Trans, Ind.App,Vol.13,NO.2,Mar/Apr,1992.

[11] Casadi Domenico, Serra Giovanni. Implementation of A Direct Torque Control Algorithm for Induction Motors Based on Discrete Space Vector Modulation[J]. IEEE Transaction on Power Electronics,2000, 15(4): 769-778.

[12] Sayeed Mir.PI and Fuzzy Estimators for Tuning the Stator Resistance in Direct Torque Control of Induction Machines.IEEE Trans.Power Electron.Vol.13, NO.2,March 1998. 